\title{
Enriching Students' Vocabulary by Implementing Semantic Mapping Strategy at the Tenth Grade of SMK Negeri 1 Ambon
}

\author{
Renata. C. G. V. Nikijuluw, S.Pd., M. TESOL \\ Pattimura University \\ Ambon, Indonesia \\ renataloppies@gmail.com
}

\author{
Stephanie Rosalina Cangkat, S.Pd \\ Pattimura University \\ Ambon, Indonesia \\ ochacangkat@gmail.com
}

\begin{abstract}
This paper aims at enriching students' vocabularies by implementing semantic mapping strategy at the tenth grade of SMK Negeri 1 Ambon. The subjects of the research were 20 students consisting of 4 males and 16 females. The research used a Classroom Action Research (CAR) where collaborated with the English Classroom teacher. The result of the study showed that in the first and the second cycle of the criterias of success were achieved, $70 \%$ of the students were successful. Based on this research, there are several advantages that was gained by the students when they learn vocabulary using Semantic Mapping Strategy in the classroom such as: students are able to understand the content of the reading text, understand the part of speech of the main word, and they also can write simple sentences. In this study, the researchers found that there was positive perception of the students toward the implementation of Semantic Mapping Strategy. The students' responses showed that by using this strategy they can enjoy learning in the classroom and their vocabularies' knowledge were enriched. Based on the test result it can be stated that Semantic Mapping Strategy is effective in enriching vocabulary and understand the meaning of new words.
\end{abstract}

Keywords: Semantic Mapping Strategy, Vocabulary

\section{INTRODUCTION}

\subsection{Background of the study}

Vocabulary is a strong foundation which must be mastered by students in learning a language. The important point in learning language is the students should have enough word knowledge. According to reference [2] "Vocabulary is the central to English language teaching because without sufficient vocabulary, students cannot understand others or express their own idea". They might have difficulties in doing many activities related with English if they do not have vocabulary. Learning vocabulary is crucial for the students because it is the first way to send a certain meaning to communicate with others, especially in English. According to Laufer in reference [7] word knowledge is one of the basic elements that has to be learnt by students.

Based on preliminary study carried out by the researcher during a one-month observation at SMK Negeri 1 Ambon, she observed and interviewed the teacher about the problems that she noticed in the classroom. The researcher observed the students when the teacher taught them in the classroom using observation checklist for three times in three weeks. After observing the students and interviewing the teacher, there was one problem mentioned by the teacher, it was students' lack of vocabularies. Based on the observation and interview, students' lack of vocabularies are caused by two factors. The first factor was the students were difficult in memorizing a new word, in this case a new word means that unfamiliar word which the teacher used during teaching and learning process, and the second factor was that students did not understand the meaning of those new words. From the above mentioned problem, students could not use language well in the classroom. It means that students' word knowledge was not adequate, therefore they had difficulty to speak, read, and write well in English.

\subsection{Problem Statement}

During her observation for approximately one month at SMK Negeri 1 Ambon, the researcher found the problem about the lack of students' vocabularies. As the result, many students cannot perform well in writing a sentence in a short paragraph. They cannot distinguish adjective and noun clearly. Students had difficulty in memorizing the new words taught by the teacher and the students also did not understand the meaning of 
the new words. As a result of having not sufficient vocabularies, the students could not write well in English. This study is aim to investigate does Semantic Mapping Strategy can help students in solving the problem.

\subsection{Research Question}

1. How can students' vocabularies of SMK Negeri 1 Ambon be developed by applying Semantic Mapping Strategy?

2. What are their perceptions toward the implementation of Semantic Mapping Strategy?

\subsection{Definition of Key Terms}

* Semantic Mapping Strategy: is a strategy that can enrich students' vocabularies at the tenth grade of SMK Negeri Ambon and also can help the students to write a simple sentence.

* Vocabulary: is a list or set of words that has to be learned by the learners before they write a simple sentence.

\section{REVIEW OF LITERATURE.}

\subsection{The Nature of Vocabulary}

Vocabulary is the important point in English which must be learned by learners before they want to master the English language skills well. Carroll's cited in reference [8] stated that vocabulary acquisition plays an important role in reaching the learning objectives. Based on the previous explanation, students must learn vocabulary because they cannot do anything related with learning English before they know and have sufficient word knowledge.

Learning word knowledge is not really easy; it is not only learning about the word but also learning about the meaning of the word. According to Stahl Steven cited in reference [22] vocabulary knowledge as the knowledge of word cannot be taught directly by giving the definition but how the word can be used. Another definition by reference [19] is that "vocabulary is the core component of language proficiency and provides much of the basis for how well learners speak, listen, read, and write". Coday as cited in reference [20] also stated that word knowledge will assist learners to produce and comprehend the language since it is considered as an important part in communicative competence. Vocabulary is very important to be learned by second language learners because it is a central bridge to build communication.

Vocabulary cannot be learnt automatically. It is a skill that should be acquired through hearing, seeing, and studying. It means that learners never get something if they do nothing.
Through having vocabulary they are able to express their opinions and communicate with others.

\subsubsection{Types of Vocabulary}

Lehr as cited in reference [23] stated that vocabulary is the meaning of words and also the word knowledge. Those are two types of vocabulary; they are active vocabulary and passive vocabulary. According to reference [18] vocabulary is divided into two parts they are about passive or receptive vocabulary and active or expressive vocabulary. An active or expressive vocabulary is a word used by a person and a passive or receptive vocabulary is a word that can be understood by person, but is not used actively.

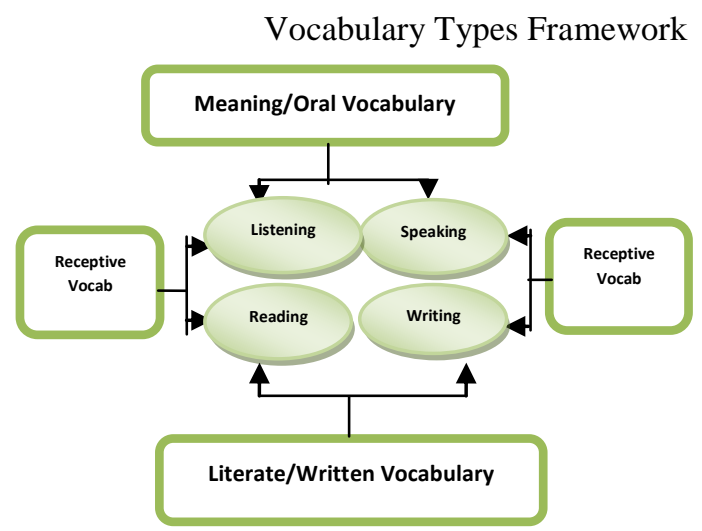

Figure 2.1.1 Vocabulary Types Vocabulary Types graphic that used in this research based on John \& Shane Templeton (2004, p. 2)

\subsubsection{Principles of Teaching Vocabulary}

Based on reference [12] in his article, there are six principles in teaching vocabulary, they are:

1. Keep the teaching simple and clear. Don't give complicated explanations.

2. Relate the present teaching to past knowledge by showing a pattern or analogy.

3. Use both oral and written presentation - write it on the whiteboard as well as explaining it.

4. Give most attention to words that are already partly known.

5. Tell the learners if it is a high frequency word that is worth nothing for future attention.

6. Don't bring in other unknown or poorly known related words like near synonyms, opposites, or members of the same lexical set. 


\subsection{The Importance of Vocabulary Teaching}

The basic thing that must be conducted by the teacher is teaching word knowledge for the students because it is an important part in learning a language. Before students are able to master other aspects in language they have to have sufficient word knowledge. Students cannot do or use other aspects in language if they do not have sufficient vocabulary. Laufer as cited in reference [13] considers vocabulary learning as the main component of language use and language learning. He also stated that vocabulary learning is one of the most essential part because it is impossible in learning a language without having vocabulary. Without having vocabulary students cannot build communication with others.

\subsection{Semantic Mapping Strategy}

\subsubsection{Definition of Semantic Mapping}

Reference [13] defined semantic mapping as a strategy that shows a graphic and the relationship between ideas and task terms. Semantic Mapping is also defined as one strategy to elaborate how to categorize word meaning. Reference [20] stated that semantic mapping is a grateful way in teaching and learning vocabulary.

\subsubsection{Procedures of Implementing Semantic Mapping}

There are procedures of Semantic Mapping Strategy modified from Center for Gifted Education, the College of reference [1]

1. Introduce Semantic Mapping Strategy. 2. Find the definition,

\section{Determines part of speech and stems.}

4. Determines the origin and word families of the word. 5. Students have to re-write the text based on the students' semantic mapping using their own word.

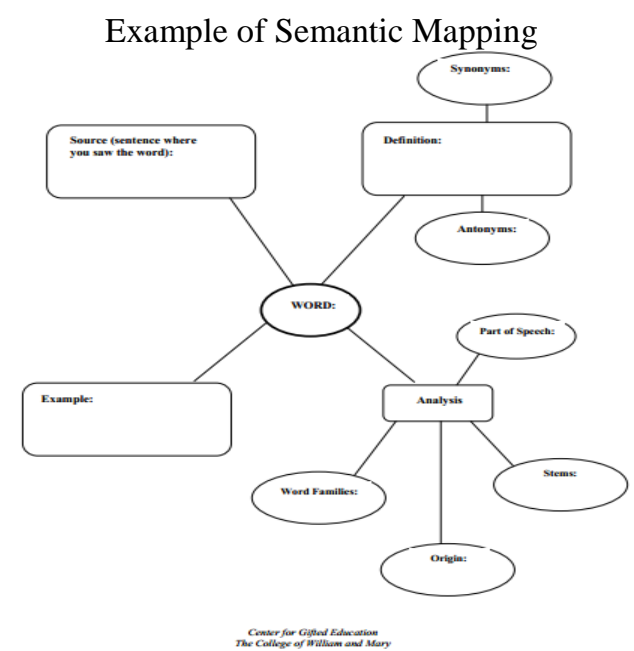

Figure 2.3.2 (1) Semantic Mapping

(Adopted from Center for Gifted Education the Collage of reference [1]

\subsubsection{The Advantages of using Semantic Mapping}

Semantic Mapping is one of the best approaches in teaching vocabulary in order to make students recognize about the relationship of the word. Graves as cited in reference [7] Debate as cited in reference [20] explains that semantic mapping as a useful way to teach vocabulary "provides the teacher with an assessment of the students' prior knowledge or schema availability on the topic". Based on reference [7] there are several advantages of implementing semantic mapping strategy in the teaching and learning of vocabulary process in the classroom such as: (1). Helping students to remember the word easily because it is organized in some categories of words, (2). Decreasing students' boredom in learning vocabulary, (3). Helping students become active participants in the class because they can have their ideas represented, (4). Increasing the students' motivation to learn new vocabularies because of the attractiveness of semantic mapping strategy in teaching vocabulary.

\section{METHODOLOGY}

\subsection{Research Design}

This study used "Classroom Action Research" (CAR) as a method to implement Semantic Mapping Strategy. According to reference [15] action research focused on the improvement which means adding knowledge when reflecting in teaching practices. This action research consisted of four steps, namely: planning, action, evaluation and reflection. Those steps are conducted in some cycles until the objectives are 
reached. It means that, if the first cycle fails the researcher must continue to the second cycle to fix the problem in the previous cycle. If the results of the second cycle reach the criteria of success, then the research can be stopped. The researcher collaborated with English teacher of SMK Negeri 1 Ambon of the tenth-eight class.This research was conducted at SMK Negeri 1 Ambon. The subject of the research was all of the students in tenth-grade with the total number of 20 students. There are consisted of 4 males and 16 females.

\section{DISCUSSION}

\subsection{Discussion}

Based on the data collected and the result of this research, it can be started that students' vocabulary was improved. The improvement can be seen through the first and second cycle of students' test result and also students' perception.

\subsubsection{The Improvement of Students' Vocabulary Using Semantic Mapping Strategy.}

The indicator of success in this research would be success if $70 \%$ of the students in the classroom who were in the "excellent" and "good" level. Meanwhile, the category of "excellent" level are about students are able to write a simple sentence, write a simple sentence with correct part of speech (noun and adjective), put the word in the right place, and write a sentence with correct punctuation and capitalization. On the contrary, the category of "good" level such as students are able to write a simple sentence, write a simple sentence with correct part of speech (noun and adjective), put the word not in the right place and write a sentence with correct punctuation and capitalization. The result of the students' test in the first cycle was 16 students $(80 \%)$ were at "excellent" and "good" level. It means that most of the students were able to write a simple sentence almost correctly. Even though they were able to write short sentences but there were four students (20\%) were at "fair" and "poor" level since they wrote the sentences in Bahasa and not in English. In this case, the category of "fair" level as a follow: students are able to write a simple sentence, write a simple sentence with correct part of speech (noun and adjective), put the word not in the right place and write a sentence with incorrect punctuation and capitalization. Besides that, the category of "unsatisfactory" level such as: students are able to write a simple sentence, write a simple sentence with incorrect part of speech, put the word not in the right place and write a sentence with not correct punctuation and capitalization. The last is "poor" and the category of it are the students are able to write a simple sentence but in Bahasa not in English, write a simple sentence with incorrect part of speech, put the word not in the right place and write a sentence with incorrect punctuation and capitalization.
Even though the indicator of success was achieved in the first cycle, the researcher continued to the second cycle to see the students' achievement in writing short paragraph from cycle 1 to cycle 2 and also to support the first cycle. In cycle 2 the students' test results showed that there was an improvement. In this cycle, there were 19 students $(95 \%)$ who passed the test and were at the "excellent" and" good" levels and there was no students who were at "poor" level. On the other words, almost all the students could write simple sentences using English, write simple sentences with correct part of speech (noun and adjective), write sentences with correct punctuation and capitalization, but there was one student who were in the fair level because he put the word not in the right place. Based on the explanation previously, students' achievements improved not only in choosing correct vocabulary but also in writing correct sentences in a short paragraph. They could write a sentence in a short paragraph using noun and adjective in the right place.

This finding is supported by reference [7] she stated in her research that the reason why students' low vocabulary mastery and memorization it can be influenced by the teacher's strategy in teaching word knowledge. According to reference [17] stated that semantic mapping as a strategy can give positive impact in improving students' vocabularies and abilities in writing correct sentences in a short paragraph. Reference [25] also stated that semantic mapping is an efficient way for increasing students' word knowledge.

\subsubsection{The Advantages and Disadvantage of Implementing Semantic Mapping Strategy in Teaching Vocabulary.}

Semantic Mapping is one of teaching vocabulary strategies that can help students in enriching their word knowledge. From the implementation, both the teacher and students gained some advantages and one disadvantage.

There are several advantages gained by the students after the implementation of Semantic Mapping Strategy. The first is that it can help the students to understand the content of the reading text. By reading the passage students found some unfamiliar words that they did not see or know before. Here, the students could use the dictionary to look up the meaning of the words and automatically their knowledge improved. The second point is that the students must determine the part of speech of the "main word". It means that in this section, Semantic Mapping can help the students in understanding the part of speech of the main word. The third advantage is that through implementing this strategy; the students are able to make simple sentences.

Semantic Mapping Strategy also gives a good impact for the teacher. This strategy can help the teacher in teaching vocabulary teaching. 
Besides the advantages of the strategy, the researcher also found one disadvantage of Semantic Mapping Strategy toward students in the classroom. This strategy only focuses on the individual work. It means that from the beginning until the end of the learning process there is no interaction among students in this strategy. In her further research, she would like to conduct study on how to use semantic mapping for group work.

\subsubsection{Students' Perception toward the Implementation of Semantic Mapping}

After finished interviewing three students, the researcher and classroom teacher reflected the students' perception toward the implementation of Semantic Mapping Strategy. In this section, the researcher found that there was a positive perception of students toward the implementation of Semantic Mapping strategy. The students' responses showed that by using this Strategy they can enjoy learning in the classroom, they can understand the meaning of unfamiliar words by looking up on the dictionary and also their vocabulary knowledge was improved.

\section{CONCLUSION AND SUGGESTION}

\subsection{Conclusion}

Based on the students' test result in the first and second cycle in this research, the researcher concluded that Semantic Mapping Strategy can enrich students' vocabulary well. It is clearly shown that there is an improvement of students' grade from the first to the second cycle. Based on the interview, students gave a positive perception about the implementation of Semantic Mapping Strategy in teaching learning vocabulary in the classroom.

Studies conducted by other researchers as mentioned previously in her paper showed that Semantic Mapping Strategy could enrich students' vocabulary and knowledge of words. In the line with these researches, the researcher also found out that in her research the students did well in enriching their vocabulary knowledge.

\subsection{Suggestion}

Based on the explanation before, the researcher puts forward some suggestions related with this research. For the teacher and other researchers, this strategy is a great one that can help students in enriching their vocabulary. Based on this research, the researcher suggests teachers and other researchers, to conduct this strategy to the students in group when using this strategy. So, the students can build a communication with each other. They can and also train to discuss and think creatively and explore their ideas. So, at the end of this lesson the students not only enrich their word knowledge but also they can improve their knowledge from their result discussion.

\section{REFERENCES}

[1] Center for Gifted Education the Collage of William and Mary. (1998). Persuasion: A language Art 3 Unit for high-ability learners. Dubuque, Lowa: Kendall Hunt Publishing.

[2] Clouston, M. L. (2013). Teaching Vocabulary: English Language Teacher Development Series. TESOL International Association.

[3] Duffy, G. G. (2009). Explaining Reading:Using Semantic Maps to Develop Word Meaning. New York: The Guilford Press.

[4] Gairns \& Redman. (1986). Working With Words. A guide to Teaching and Learning Vocabulary. Cambridge: Cambridge hanbooks for language learners: Cambridge University Press.

[5] Hall, T. (2002). Graphic Organizer. Nation Center on Accessing the General Curriculum , 1-8.

[6] Hatch, E., \& Brown, C. (1995). Vocabulary, semantics and language education. Cambridge: Cambridge University Press.

[7] Indriati. (2014). The Effectiveness of Semantic Mapping Strategy to Improve Students' Vocabulary Mastery. Journal of English Language Teaching , 7687.

[8] McKweon, M. G. (1987). The Nature of Vocabulary Acquisition. New York: Psychology Press.

[9] Menengah, D. J. (2015). Panduan Penilaian untuk Sekolah Menengah Atas. Jakarta.

[10] Mertler, C. A. (2001). Practical Assessment, Research \& Evaluation . A peer-reviewed electronic journal .

[11] Nae'em, O. (2013). The Effect Of Teaching Vocabulary through Semantic Mapping on EFL Learners' Awareness of Vocabulary Knowledge at AL Imam Mohammed Ibin Saud Islamic University. International Interdisciplinary Journal of Education , Vol 2, issue 7, $722-731$.

[12] Nation, P. (n.d.). Teaching Vocabulary. Asian EFL Journal . 
[13] Nilforoushan, S. (2012). The Effect of Teaching Vocabulary through Semantic Mapping on EFL Learners' Awareness of the Affective Dimensions of Deep Vocabulary Knowledge. English Language Teaching, Vol.5, No. 10, 164-172.

[14] NSW, G. (n.d.). Vocabulary- Semantic Mapping. NSW Centre for Effective Reading, 1-6.

[15] Nugent, G. (2001). A Practical Guide to Action Research for Literacy Education. Washington, DC: International Reading Association.

[16] Passuello, L. (2016). Top 3 Reasons to Improve Your Vocabulary. Retrieved April 24, 2016, from Litemind: https://limited.com/top-3-reasons-to-improve-yourvocabulary

[17] Piettelman, S. (1985). Project on the Investigation of the Effectiveness Vocabulary Instruction. ERIC (Document Reproduction Service No. ED 276988) , 117.

[18] Pikulski, J. (2004). Teaching and Developing Vocabulary: Key to Long-Terms Reading Success. Houghton Mifflin Reading, 1-12.

[19]Richards and Renadya. (2002). Methodology in Language Teaching : An Anthology of Current Practice. Cambridge: Cambridge Univeristy Press.
[20] Saeidi and Atmani. (2010). Teaching Vocabulary through Semantic Mapping as a Pre-Reading Activity Across Genders. Journal of English Studies , 51-64.

[21] Sianturi, D. (2013). The Use of Semantic Mapping to Improve Students' Vocabulary. 1-8.

[22] Sturza, A. (n.d).Approach to Teaching and Developing Vocabulary.570-575.

[23] Thuy, N. N. (2010). The Effect of Semantic Mapping on Vocabulary Memorizing. Asian EFL Journal Quartertly, 628-659.

[24] Wintergrest, A. C. DeCapua, A., \& Itzen, R. C. (2001). The construct validilty of one learning instrument. System, 29,385-403.

[25]Zaid. (1995). Semantic Mapping in Communicative Language Teaching. English Teaching Forum , 33 (3). 